Revista Eletrônica do Mestrado

Profissional em Administração da UnP

edunp

V. 12, N. 1, 2020

ISSN 1984-4204

https://repositorio.unp.br/index.php/raunp

https://doi.org/10.21714/raunp.v12i1.1901

\title{
Proposta de ações sustentáveis a uma empresa distribuidora-atacadista de frota rodoviária
}

\section{Proposal of sustainable actions to a company distributor-wholesaler of road fleet}

\author{
Etienne Cardoso Abdala ${ }^{\mathrm{a}}$, Arthur Silva Rosa ${ }^{\mathrm{b}}$, Luciana Oranges ${ }^{\mathrm{c}}$ \\ aDDoutorado em Administração de Empresas. Universidade Federal de Uberlândia. E-mail: etienneabdala@hotmail.com

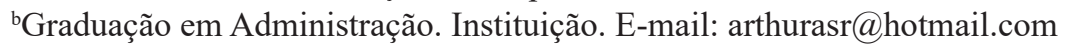 \\ 'Doutorado em Administração. Instituição. E-mail: lcezarino@gmail.com
}

\begin{abstract}
Resumo
Muito se discute sobre a responsabilidade das empresas distribuidoras-atacadistas no contexto de desenvolvimento sustentável. O objetivo deste trabalho foi analisar as práticas sustentáveis realizadas por uma empresa deste setor de Uberlândia-MG e de sua cadeia de suprimentos e propor ações estratégicas utilizando-se a ferramenta de análise sistêmica Soft System Methodology (SSM) em busca do desenvolvimento sustentável. Por meio da pesquisa qualitativa foi possível considerar que uma possível agenda levaria à identificação de variáveis em comum para este ramo de atividade: o trabalho social, a melhoria da frota e do descarte de resíduos e, o investimento no motorista. Além disso os resultados também apontam a alta importância de uma organização fazer parte de uma cadeia de suprimentos sustentável e que a adoção de práticas sustentáveis pode levar a redução de custos e melhoria na imagem da empresa. Por fim, para contribuições futuras, é necessário o aprofundamento dos questionamentos com outras empresas do setor distribuidor-atacadista para a comparação das ações e possíveis parcerias nas variáveis encontradas pelo método utilizado (SSM).
\end{abstract}

Palavras-chave: Práticas sustentáveis; Soft System Methodology; Sustentabilidade; Cadeia de Suprimentos.

\begin{abstract}
There is much discussion about the responsibility of wholesale-distributors in the context of sustainable development. The objective of this work was to analyze the sustainable practices carried out by a company from this sector of Uberlândia-MG and its supply chain and propose strategic actions using the systemic analysis tool Soft System Methodology (SSM) in search of sustainable development. Through qualitative research it was possible to consider that a possible agenda would lead to the identification of common variables for this branch of activity: social work, fleet improvement and waste disposal, and investment in the driver. In addition, the results also point to the high importance of an organization being part of a sustainable supply chain and that the adoption of sustainable practices can lead to cost reduction and improvement of the company image. Finally, for future contributions, it is necessary to deepen the inquiries with other companies in the wholesale-distributor sector for the comparison of actions and possible partnerships in the variables found by the method used (SSM).
\end{abstract}

Keywords: Sustainable Practices; Soft System Methodology; Sustainable; Supply Chain. 


\section{Introdução}

Com o passar do tempo, a percepção de que os recursos naturais eram infinitos foi mudando, com o aumento da população e do consumo, ficou claro que os recursos não se renovavam na mesma velocidade. Então, no ano de 1972 na Conferência de Estocolmo (Suécia) se inicia uma discussão mundial a respeito da ecologia e preservação da natureza e em seguida no Relatório de Brundtland (1987), surge o conceito de sustentabilidade. Sua definição mais conhecida é a de preservar o meio ambiente para que as futuras gerações consigam atender às suas necessidades, e garantir o desenvolvimento social e econômico (Relatório da Comissão Mundial sobre Meio Ambiente e Desenvolvimento, ONU, 1987).

De forma geral, a sustentabilidade visa integrar os três grandes pilares da sociedade, conhecidos como o "Triple Bottom Line" formado pelas dimensões economicamente viável, socialmente justa e ambientalmente correta (Elkington, 1994).

O Brasil sempre esteve inserido no contexto mundial da sustentabilidade, seja como ícone por possuir a Amazônia, maior floresta tropical do mundo, ou por ser um país emergente sem medidas rígidas ao controle da degradação ambiental, especialmente na área de construção e transporte.

Um dos primeiros programas do governo de transporte rodoviário no Brasil foi o Plano de Viação, em 1934. Mais tarde, no governo de Juscelino Kubitschek (1956-1961), houve incentivo à construção de rodovias que, segundo dados oriundos do "Projeto de Reavaliação de Estimativas e Metas do Plano Nacional de Logística e Transportes" do Ministério do Transporte, no ano de 2011, levaram ao crescimento contínuo deste modal representando hoje, $52 \%$ de todos os tipos de transporte utilizados.

Segundo a Divisão Estatística das Nações Unidas (UNSD), as empresas atacadistas são aquelas que revendem grande quantidade de produtos a preços mais baratos. Os atacadistas embalam, separam e classificam as mercadorias em lotes e então distribuem. Normalmente, as empresas atacadistas operam também na distribuição dos produtos, repassando os produtos que dispõe aos comerciantes, sendo então consideradas empresas distribuidora-atacadistas.

Na cidade de Uberlândia (MG) há uma concentração de empresas desta natureza tornando o assunto mais crítico e fazendo com que a cidade busque ser um exemplo de práticas sustentáveis voltadas ao setor.

Para cumprir com as exigências desse mercado competitivo, as empresas distribuidora-atacadistas têm discutido frequentemente sobre os principais problemas ambientais do mundo e, já que essas empresas possuem poder econômico e consequentemente poder persuasivo, ditam quais medidas devem ser tomadas para diminuir e até evitar tais problemas (Carvalho \& Hourneaux Júnior, 2012).

E é nesse contexto de concorrência aliado à nova consciência que entram as estratégias de sustentabilidade. As mudanças feitas dentro do setor devem estar relacionadas com a demanda social, mudando o estilo de vida das pessoas e buscando a produção de bens e serviços dentro de uma gestão ambiental correta (Mattos, 2001). Para introduzir a sustentabilidade são necessárias inovações, novas tecnologias, adotar práticas de responsabilidade social, além de realizar reciclagem, reutilização e destinação correta dos materiais, entre outras (Orsato \& Wells, 2007).

As empresas fazem parte de uma grande rede de organizações que de forma geral, compram matéria prima, armazenam, agregam valor, transportam e liberam determinado produto ou serviço para outros membros da cadeia, sempre com o objetivo de atender as necessidades de seus clientes. Essa rede de organizações é chamada de Supply Chain (SC) e a integração de todas as suas atividades, com cooperação e um bom relacionamento entre os membros da cadeia, de modo que atinjam objetivos em comum, é conhecida como 
Supply Chain Management (SCM) (Ching, 2007; Pires, 2004).

Com os avanços nos estudos tanto na SCM quanto na sustentabilidade, desenvolve-se a Sustainable Supply Chain Management (SSCM), que consiste na aplicação dos três âmbitos do Triple Bottom Line (TBL) em uma cadeia de suprimentos, que além de atender às demandas dos stakeholders, promove vantagens para os membros da cadeia, dentre elas redução de custos e vantagem competitiva (Seuring \& Müller, 2008).

As pressões exercidas pelos stakeholders e pela legislação por práticas sustentáveis que contemplem o TBL, aliados ao progresso nos estudos da SCM, foi desenvolvida a Sustainable Supply Chain Management (SSCM). Nesse sentido a cadeia de fornecimento como um todo deve buscar pela aplicação do âmbito social, econômico e ambiental nas suas atividades. Para isto, os membros da cadeia de suprimentos devem definir objetivos para obter um bom desempenho nas três dimensões da sustentabilidade, e cada organização que compõe a rede empresas deve se engajar a atingi-los, e desta forma, permanecer na cadeia de suprimentos (Pagell \& Wu, 2009; Seuring \& Müller, 2008).

O fato de o setor rodoviário ter um referencial de mais de cem anos de existência com um paradigma de produção existente há décadas (Orsato \& Wells, 2007), apresenta uma visão enraizada e consolidada, sendo então um fator que dificulte a adoção e incorporação da sustentabilidade.

Não se pode esquecer o nível de competitividade vivido por estas empresas, o ambiente empresarial tem se intensificado em concorrência, além dos altos juros, da alta da inflação, da queda no poder aquisitivo das pessoas e outras consequências que pioram o cenário administrativo das empresas.

Pelo fato de a sustentabilidade ser uma questão complexa, pois apresenta variáveis que são interdependentes (social, ambiental e econômico), abordagens simplistas podem não conter a complexidade do tema, forçando o pesquisador a buscar abordagens mais abrangentes, com enfoque sistêmico (Cezarino, Liboni \& Martinelli, 2005) para conseguir atingir o objetivo deste trabalho de propor ações de sustentabilidade dentro de uma empresa distribuidora-atacadista de Uberlândia- MG, faz-se necessário utilizar a ferramenta de análise sistêmica Soft System Methodology (SSM).

\section{Referencial teórico}

\subsection{Cadeia de suprimentos sustentável}

O Council of Supply Chain Management Professional (CSCMP, 2009) define logística como "parte da Cadeia de Suprimentos que planeja, implementa e controla, de como eficiente e eficaz, o fluxo direto e reverso e a armazenagem de bens, serviços e informações [...]" e Ballou (2001) reforça que a logística busca entregar o produto correto, no tempo determinado e da maneira adequada, sendo de suma importância para as organizações atenderem aos requisitos dos clientes.

Já o termo Supply Chain (SC) envolve toda a rede de organizações autônomas ou semi-autônomas que são responsáveis por adquirir recursos, agregar valor e liberar determinado produto ou serviço (Pires, 2004). Bertaglia (2009) define cadeia de suprimento como um conjunto de movimentações necessárias para uma empresa obter os recursos necessários para a produção de produtos ou serviços que atendam às necessidades dos clientes, em termo de tempo, qualidade e local. Também é definida como a integração de todas as atividades (produção, armazenamento e transporte), desde o consumidor final até o fornecedor inicial, de modo que se minimize os custos e maximize o valor percebido pelos consumidores (Bond, 2002; Novaes, 2007).

A Supply Chain Management (SCM), cuja tradução é gestão da cadeia de suprimento, foi definida pelo CSCMP 
(2009) da seguinte maneira:

[...] o planejamento e a gestão de todas as atividades envolvidas no fornecimento e aquisição, conversão e todas as atividades de gestão logística. Importante, também inclui a coordenação e colaboração com parceiros do canal, que podem ser fornecedores, intermediários, prestadores de serviços terceirizados e clientes. Em essência, a gestão da cadeia de suprimentos integra a gestão da demanda e do fornecimento dentro e entre as empresas (CSCMP, 2009, p.1).

Nesse sentido a SCM refere-se ao gerenciamento da integração de todas as atividades (fluxo de mercadorias, informações e recursos) de uma cadeia, priorizando as relações inter-organizacionais e a cooperação entre os membros a fim de se atingir um objetivo comum (Ching, 2007). Desta forma, o gerenciamento da cadeia de suprimentos busca a redução dos custos e desperdícios organizacionais, aumentar a qualidade e flexibilidade além de estar diretamente relacionada com o nível de serviço oferecido ao cliente, com isso, através do gerenciamento bem implementado, pode-se aumentar os lucros organizacionais, atingir novos cliente, e aumentar a competitividade (Ballou, 2001). Assim, Ballou (2001) demonstra a importância da SCM para as organizações com o foco estratégico.

Wood Junior (1998) corrobora com Ballou (2001) em diversos pontos no SCM como a redução de custos e valor percebido pelo cliente, mas ressalta a sua importância na redução de estoques, na cooperação dos fornecedores e no desenvolvimento de novos produtos para determinada empresa. Christopher (2007) complementa que a cooperação e o bom relacionamento com os membros da cadeia (auxiliados pela Tecnologia da Informação) proporciona uma vantagem competitiva superior e duradoura em relação a seus concorrentes.

As pressões exercidas pelos stakeholders e pela legislação por práticas sustentáveis que contemplem o TBL, aliados ao progresso nos estudos da SCM, foi desenvolvida a Sustainable Supply Chain Management (SSCM). Nesse sentido a cadeia de fornecimento como um todo deve buscar pela aplicação do âmbito social, econômico e ambiental nas suas atividades. Para isto, os membros da cadeia de suprimentos devem definir objetivos para obter um bom desempenho nas três dimensões da sustentabilidade, e cada organização que compõe a rede empresas deve se engajar a atingi-los, e desta forma, permanecer na cadeia de suprimentos (Pagell \& Wu, 2009; Seuring \& Müller, 2008).

As cadeias de suprimentos sustentáveis caracterizam-se pela alta cooperação entre seus membros e os stakeholders para atingir objetivos em conjunto. Além disso apresentam relações de longo prazo com os fornecedores, alinhamento de práticas sustentáveis ao longo da cadeia, certificações e avaliações constantes quanto à adequação às práticas do Triple Botton Line. Dentre os benefícios de pertencer a uma SSC apontoados pelos autores estão a redução de custos e a vantagem competitiva (Pagell \& Wu, 2009; Seuring \& Müller, 2008; Vachon \& Klassen, 2006).

Os chamados nodais são considerados os locais em trechos privilegiados da rede rodoviária nacional, que possui uma facilidade de acesso aos demais modais de transporte, são pontos estratégicos no que se refere à expedição, à transferência de carga e capacidade de armazenagem e, à mão de obra qualificada para realização de tarefas tanto administrativas quanto operacionais no TRC (Huertas, 2014).

\subsection{Logística e distribuição na cidade de Uberlândia - MG}

A cidade de Uberlândia é considerada um modal, sendo o epicentro logístico do setor atacadistadistribuidor. Seus eixos rodoviários centrais são as BRs 050, 365 e 452 que ligam Brasília ao norte - divisa MG/SP ao sul; Montes Claros ao leste - São Simão a oeste; e Uberlândia - Araxá, respectivamente (Huertas, 
2014).

A importância da cidade de Uberlândia no modal rodoviário como polo atacadista e distribuidor começa no século XVIII por ser considerado um ponto estratégico para abastecimento na rota São PauloGoiás (Huertas, 2014).

Com a construção e o asfaltamento das rodovias, juntamente com o fato de estar localizada em uma posição privilegiada no centro do Brasil (Da Silva, et al., 2000), aqueceu-se ainda mais as atividades comerciais em Uberlândia, principalmente o comércio atacadista e então, nesse período de crescimento, há o surgimento e consequente consolidação das cinco empresas atacadistas e distribuidoras atuais do município: Aliança, Arcom, Martins, Peixoto e União (Huertas, 2014).

Portanto isso mostra qual é um dos principais desafios para o setor atacadista e varejista não só da cidade em questão, como do país todo: a logística de distribuição, pois como consequência da proliferação territorial do consumo de produtos por parte da população, é possível afirmar que em algum ponto de sua escala de atuação, as empresas atacadistas e distribuidoras contratam o serviço de transporte, tornando-as então embarcadoras (Xavier, 2009 apud Huertas, 2014).

\subsection{Teoria geral de sistemas (TGS)}

Os pioneiros na abordagem sistêmica foram Ludwig Von Bertalanffy e Kenneth Boulding que desenvolveram um novo conceito, uma metodologia que tivesse a capacidade de explicar questões mais complexas (Venturi et al., 2005).

A abordagem sistêmica apresenta um extenso olhar para o todo e não apenas uma análise específica das partes, aumentando a efetividade da resolução de problemas. Essa melhora na efetividade acontece pelo fato de que com o aumento da complexidade nos projetos e nos sistemas em geral, percebeu-se que a solução de problemas isolados é insuficiente (Venturi et al., 2005). A TGS tem a capacidade de fornecer modelos que podem ser utilizados em diferentes fenômenos de diversos domínios por serem interdisciplinares (Do Vale, 2013).

\subsection{Soft Systems Methodology (SSM)}

Os hard-systems, na tradução "sistemas duros", são utilizados principalmente em situações bem estruturadas, que são mais fáceis de serem medidas e quantificadas e com um alto grau de previsibilidade (Martinelli \& Ventura, 2005).

A resolução de problemas, que envolvem diversos grupos de pessoas com diferentes visões e interesses na organização, demanda maior enfoque para estudos que encontrem maneiras para que, qualquer tipo de intervenção para solucionar tal problema acomode os desejos dos diversos envolvidos (Júnior, et al., 2007).

Checkland ao tentar aplicar a abordagem hard em problemas de gestão, que apresentam situações nas quais os objetivos normalmente não são bem definidos e nem precisos, percebeu que essa metodologia não surtia o efeito necessário e então sugeriu uma mudança sistêmica para os soft-systems, na tradução "sistemas macios" (Gonçalves in Martinelli \& Ventura, 2005 apud Venturi et al., 2005).

Em 1970, o trabalho de pesquisa liderado por Peter Checkland ganhou forma (Gonçalves in Martinelli \& Ventura, 2005 apud Venturi et al., 2005). A SSM (Soft System Methodology) foi desenvolvida com a finalidade de tentar resolver problemas de empresas pouco ou nada estruturados ou até obscuros, através do mapeamento das situações pelas perspectivas empírica e teórica e confrontação de ambas para sugerir 
mudanças que sejam sistematicamente desejáveis sem que haja mudanças na cultura da empresa (Checkland, 2000 apud Ferolla et al., 2012). Portanto, a SSM é uma ferramenta com grande importância em situações problemáticas complexas por permitir a visão das diferentes perspectivas presentes no sistema (Cezarino, Liboni \& Martinelli, 2005).

Na prática, Checkland (1981) propôs um modelo com sete passos para a aplicação da SSM. Os passos 1, 2, 5, 6 e 7 são ações que ocorrem no "mundo real" e os passos 3 e 4 ocorrem no "mundo sistêmico" (Venturi et al., 2005). Então, de acordo com Venturi et al. (2005), os sete passos serão descritos a seguir para melhor entendimento da metodologia SSM.

No passo 1, chamado de "Situação Problemática Desestruturada" procura observar uma situação problemática mal definida e então reunir o maior número possível de informações sobre esta.

Lembrando que, uma das principais vantagens da SSM é a consideração das diferentes visões de mundo dentro do sistema com relação ao problema encontrado, portanto sempre é necessário captar essas "weltanschauungen" de todos os indivíduos envolvidos.

No passo 2, chamado de "Definição da situação problema", é definido a situação em que o problema ocorre e a melhor forma de defini-la é através de figuras ricas, que é um desenho que se assemelha à um mapa mental que conecta as diferentes perspectivas dos stakeholders à estruturação do problema.

No terceiro passo, há a discussão e a formulação das definições essenciais, chamadas de "root definitions", presentes no sistema. Tais definições são avaliadas a partir de uma técnica de modelagem sistêmica chamada pelo mnemônico inglês "CATWOE", que significa Customers (clientes), Actors (atores), Transformation (transformação), Word Vision (do alemão weltancshauung, traduzido visão de mundo), Owner (proprietário) e Environmental Constraints (restrições ambientais).

De forma geral, o CATWOE é resumido de acordo com a figura a seguir:

\begin{tabular}{|c|c|}
\hline C & Aqueles beneficiados pela transformação $(\mathrm{T})$ \\
\hline $\mathbf{A}$ & Aqueles que realizam a transformação $(\mathrm{T})$ \\
\hline $\mathbf{T}$ & Os imputs sendo transformados em outputs \\
\hline $\mathbf{W}$ & Aquilo que dá significado e importância para a transformação $(\mathrm{T})$ \\
\hline $\mathbf{O}$ & Aquele que pode parar o funcionamento da transformação $(\mathrm{T})$ \\
\hline $\mathbf{E}$ & Aquilo que pode impedir as atividades do sistema \\
\hline
\end{tabular}

Fig.1. Descrição da ferramenta CATWOE

Fonte: Adaptado de Ferolla et al. (2012).

No passo 4, com base nas definições essenciais feitas no passo anterior, há a elaboração de modelos conceituais ideais, que é um aglomerado de atividades necessárias para que os objetivos que foram prédeterminados sejam atingidos.

No quinto passo, há uma comparação dos passos 4 com o 2, ou seja, as ações necessárias propostas no passo anterior são comparadas com a realidade que foi expressa na fase 2. Nesse passo é indispensável que todos os indivíduos envolvidos no sistema participem para manifestarem suas diferentes visões de mundo sobre a situação em questão.

No passo 6, há a seleção de mudanças a serem implementadas, que vão desde mudanças estruturais até mudanças de procedimentos ou atividades. A escolha das mudanças propostas no passo 5 é discutida para verificar a aceitabilidade e a viabilidade tanto financeira quanto social, ou seja, se ela será incorporada pela cultura existente na empresa. 
E finalmente o sétimo passo é a fase em que se discute e decide como as ações escolhidas serão implementadas, quem serão os envolvidos para que as ações deem certo, onde e quando elas acontecerão. E então, tendo as respostas dessa discussão de maneira que todos os envolvidos sejam ouvidos e suas diferentes visões sejam levadas em consideração, elabora-se uma agenda na qual se detalha todos os itens discutidos anteriormente.

\section{Metodologia}

Foi realizada uma pesquisa exploratória cuja definição é de uma pesquisa realizada em uma área na qual há pouco conhecimento acumulado e sistematizado (Vergara, 2000). Esta normalmente é abordada com entrevistas aos envolvidos para que se consiga entender e levar em consideração as experiências, a cultura e realidade de cada indivíduo (Piovesan \& Temporini, 1995).

O objeto de estudo foi uma das cinco maiores distribuidora-atacadistas da cidade de Uberlândia-MG, cujo nome não será mencionado por questões de ética.

Para realizar a pesquisa exploratória, utilizou-se a metodologia qualitativa denominada Soft System Methodology para a coleta de dados e, após a aplicação de seus sete passos, fez-se a análise de resultados (Checkland, 1981; Venturi et al., 2005).

Nesse sentido para se obter diferentes visões da situação problema conforme proposta pela SSM, ou seja, obter diferentes visões em relação a sustentabilidade da empresa focal, foram entrevistados funcionários de diversos níveis organizacionais, como o diretor de compras, o gestor de logística, o gestor de risco e meio ambiente, a coordenadora do instituto social e o gerente da empresa (Patching, 1992; Venturi et al., 2005)

O roteiro de perguntas foi dividido em quatro blocos: no bloco 1 foram feitas perguntas introdutórias, para saber como surgiu a empresa, quais foram seus primeiros produtos, qual é o carro-chefe atualmente; no bloco 2 foram feitas perguntas relacionadas a sustentabilidade da empresa focal (fatores sociais, ambientais e econômicos) e a de sua cadeia de suprimentos; e nos blocos 3 e 4 as perguntas deram enfoque para a questão ambiental, sobre como a empresa vê a questão ambiental aplicada ao setor distribuidor-atacadista e se ela tem planos para melhorar tal questão. As perguntas referentes a sustentabilidade da empresa e de sua cadeia de suprimentos foram elaboradas com base nos estudos de Coral (2002), Pullman, Maloni e Carter (2009), Pagell e Wu (2009) e Vachon e Klassen (2006).

\section{Análise dos resultados}

Teve-se como base que a situação-problema presente na empresa que foi objeto de estudo é a questão da sustentabilidade. Desta forma, o quadro abaixo apresenta um panorama das principais ações (práticas) sustentáveis que a empresa realiza de acordo com as três dimensões do Triple Bottom Line:

\begin{tabular}{|l|l|}
\hline Categoria & Práticas Sustentáveis \\
\hline Processos operacionais & Utilização de caixas plásticas reutilizáveis na separação dos pedidos; \\
& Reaproveitamento das caixas de papelão dos fornecedores para o envio de pedidos; \\
& Logística reversa com as caixas de papelão (cliente-empresa), sendo reutilizadas quando \\
& não apresentam danos; \\
& Possui um fornecedor de caixas recicladas caso precise de caixas extras para embalar os \\
& pedidos; \\
& Reciclagem ou destinação correta dos rejeitos (fitilho e caixas danificadas). \\
\hline
\end{tabular}




\begin{tabular}{|c|c|}
\hline Ações internas & $\begin{array}{l}\text { Utilização de lâmpadas de LED; } \\
\text { Controle do consumo de energia elétrica, visando sua redução; } \\
\text { Controle do consumo de papéis (impressão); } \\
\text { Manutenção periódica da frota para evitar o aumento da emissão dos poluentes, aderência } \\
\text { ao sistema do Arla 32, e veículos com selo de compromisso com meio ambiente; } \\
\text { Doação dos produtos com vencimento próximo ou o descarte correto; } \\
\text { Ações recreativas para os funcionários promovidas pelo RH, realização de ginastica } \\
\text { laboral, disponibilização de academia, projeto para conclusão do ensino médio para os } \\
\text { funcionários operacionais, segurança do trabalho, dentre outros; } \\
\text { Certificações como Great Pleace to Work, contratação de empresas para auditar os de- } \\
\text { monstrativos; } \\
\text { Classificação nota A pela Fitch Ratings Criação da Universidade Z Sistema de rotei- } \\
\text { rização }\end{array}$ \\
\hline Ações realizadas pelo Instituto W & $\begin{array}{l}\text { Projetos de cunho socioambiental, com o ZAPe! que visa formar jovens e adolescentes no } \\
\text { que diz respeito ao empreendedorismo, o VemSer que mobiliza os próprios funcionários } \\
\text { da empresa a realizar diversas ações sociais para a comunidade, e inúmeras parcerias } \\
\text { que permitem que o instituto tenha um impacto no ambiento nacional, como a FAS - } \\
\text { Fundação Amazonas Sustentável. }\end{array}$ \\
\hline Influência da legislação & $\begin{array}{l}\text { Exigências do IBAMA para o transporte de produtos com alta periculosidade, como paga- } \\
\text { mento de taxas e documentação especifica; } \\
\text { Treinamento dos motoristas; } \\
\text { Desenvolvimento do cofre de carga como inovação por iniciativa da própria empresa; } \\
\text { Apoio no processo de desenvolvimento de novas regulamentações. }\end{array}$ \\
\hline Impacto na imagem da empresa & $\begin{array}{l}\text { Imagem como maior patrimônio da empresa; } \\
\text { A sustentabilidade está diretamente ligada à imagem da organização; } \\
\text { Sustentabilidade como meio de se manter competitivo no mercado; } \\
\text { Criação do Instituto W e do departamento de Risco e meio ambiente; } \\
\text { A empresa exige certificações dos fornecedores e dos clientes. }\end{array}$ \\
\hline Práticas dos fornecedores & $\begin{array}{l}\text { Possuem certificações; contratos de longo prazo; bom relacionamento entre empresa- for- } \\
\text { necedor; relação "ganha-ganha"; reuniões Top to Top. }\end{array}$ \\
\hline Avaliação de fornecedores & $\begin{array}{l}\text { São constantemente avaliados quanto a qualidade do atendimento, facilidade de contato } \\
\text { com o presidente da empresa, entrega do produto conforme o combinado, a flexibili- } \\
\text { dade perante instabilidades no mercado, e a sustentabilidade. Caso as exigências quanto } \\
\text { a sustentáveis não sejam cumpridas, os negócios com o fornecedor são interrompidos. } \\
\text { Possuem auxílio de um software para avaliação }\end{array}$ \\
\hline $\begin{array}{l}\text { Ações em conjunto com a cadeia } \\
\text { de suprimentos }\end{array}$ & $\begin{array}{l}\text { Parcerias para a preservação ambiental, destinação correta de produtos avariados, ações } \\
\text { para comunidade, logística reversa, e os fornecedores ou clientes podem apoiar qualquer } \\
\text { projeto do instituto W. }\end{array}$ \\
\hline
\end{tabular}

Quadro 1. Práticas sustentáveis realizadas pelo distribuidor-atacadista.

Fonte: Elaborado pelo autor.

Observa-se que o distribuidor-atacadista possui ciência da importância da sustentabilidade em sua empresa e na de todos os membros de sua cadeia de suprimentos, tanto pela questão ética e o compromisso da empresa com a sociedade, quanto pela questão do risco de autuação, tendo em vista que uma empresa "não sustentável" possui risco de ter suas atividades interrompidas, o que afetaria o fluxo de toda a cadeia de fornecimento e poderia afetar negativamente a sua imagem e a dos membros da rede (Pagell \& Wu, 2009).

Além de minimizar os impactos negativos das atividades organizacionais no meio ambiente e na sociedade, o atacadista também percebe a sustentabilidade como forma de reduzir custos, como por exemplo a substituição de lâmpadas tradicionais pelas de LED, logística reversa e consumo de combustível. Também é percebida como forma melhorar a imagem da empresa através das ações do instituto social, por exemplo (Seuring \& Müller, 2008). 


\subsection{Primeiro passo}

Sendo assim, foram analisados vários impactos que podem ser gerados direta e indiretamente por empresas desse ramo e então classificados como fatores internos e externos, respectivamente.

\begin{tabular}{|c|c|}
\hline Fatores Externos & Fatores Internos \\
\hline Intensificação do tráfego de veículos pesados & $\begin{array}{l}\text { Alteração da qualidade do solo e das águas devido à } \\
\text { vazamento de produtos }\end{array}$ \\
\hline Aumento do risco de acidentes rodoviários & Geração de partícula dos gases e fumaça \\
\hline $\begin{array}{l}\text { Aumento do uso e extração de combustíveis fósseis } \\
\text { ou não renováveis }\end{array}$ & Geração de odores na água e no ar \\
\hline Aumento da degradação das rodovias & Atendimento as normas de segurança \\
\hline Inicia ou intensifica processos erosivos & Qualidade de vida dos motoristas \\
\hline Intensificação do aquecimento global & Investimentos na frota \\
\hline Diminuição da camada de ozônio & Geração de ruídos e vibrações \\
\hline Áreas degradadas & $\begin{array}{c}\text { Alteração da qualidade do solo e das águas devido a } \\
\text { disposição inadequada de resíduos }\end{array}$ \\
\hline Perda da conectividade e da permeabilidade & Alteração da qualidade do ar \\
\hline Desmobilização de mão de obra & Contratação de trabalhadores \\
\hline \multirow{4}{*}{ Perda de vegetação e habitat } & Alteração da cultura de populações próximas \\
\hline & Combustível utilizado \\
\hline & Tamanho e cubagem dos veículos \\
\hline & Afungentamento da fauna \\
\hline
\end{tabular}

Quadro 2. Fatores externos e internos relacionados à Logística e Distribuição.

Fonte: Adaptado de MRS Estudos Ambientais Ltda. (2005)

\subsection{Segundo passo}

Com base nos fatores citados, foi feito o questionário à empresa contendo os quatro blocos já mencionados, obtendo as seguintes respostas:

A empresa surgiu em 1995 com a junção de duas outras empresas e desde o início era uma atacadista. Como carro chefe, a empresa não possui um produto específico, ela transporta um mix que vai de alimentos a produtos de beleza e limpeza. Sua função na gestão da cadeia de suprimentos é comprar diretamente os produtos da indústria, transportá-los e vendê-los. Ela possui filiais em Minas Gerais, São Paulo, Distrito Federal, Rio de Janeiro, Espírito Santo e Bahia.

Os impactos diretamente gerados pela empresa de distribuição foram divididos em fatores sociais, ambientais e econômicos. 
Geração de ruidos e vibrações

Geração de particula dos gases e fumaças

Contratação de trabalhadores

Alteração da cultura de populações lindeiras

Atendimento as normas de segurança

Qualidade de vida dos motoristas
Geração de odores na água e no ar

Alteração da qualidade do solo e/ou das águas devido a vazamento/ derramamento de produtos perigosos

Alteração da qualidade do solo e/ou das águas subterrâneas devido a disposição inadequada de resíduos sólidos

Alteração da qualidade do ar

Afugentamento e distúrbios (extinção, atropelamento) da fauna
Investimentos na frota

Combustível utilizado

Tamanho e cubagem dos veículos

Quadro 3. Divisão dos fatores internos da empresa de Logística e Distribuição

Fonte: Elaborado pelo autor.

Foram então divididas as respostas fornecidas pela empresa nesses três fatores para o diagnóstico desta, ou seja, verificar o que é feito e o que não é feito para tais aspectos.

\begin{tabular}{|c|c|}
\hline FATOR & REVISTAS FORNECIDAS \\
\hline \multirow{10}{*}{ SOCIAL } & A maioria dos motoristas é contratado pela própria empresa \\
\hline & Motoristas recebem treinamento adequado \\
\hline & Os funcionários da empresa tem direito ao plano de saúde \\
\hline & Não há diferença de benefícios entre os motoristas e os demais funcionários \\
\hline & Existe um acompanhamento social do motorista \\
\hline & Uso de uma caixinha de sugestões \\
\hline & A empresa realiza a SIPAT \\
\hline & A maioria dos motoristas são homens com escolaridade até o primeiro grau completo \\
\hline & Não realiza pesquisas para saber a opinião do trabalhador com realação ao seu emprego \\
\hline & Não faz parte do programa Na Mão Certa \\
\hline \multirow{4}{*}{ AMBIENTAL } & $\begin{array}{l}\text { E feita a divisão dos resíduos sólidos em: recicláveis, lixo comum e avarias e todos possuem } \\
\text { descarte correto }\end{array}$ \\
\hline & Os veículos são monitorados com relação aos ruídos \\
\hline & Os veículos são sempre monitorados após chegarem de viagem \\
\hline & $\begin{array}{l}\text { Os veículos não possuem mecanismos para evitar ou diminuir a geração de odores e nem } \\
\text { emissão de partícula dos gases e fumaças }\end{array}$ \\
\hline \multirow{6}{*}{ ECONÔMICO } & Possui frota $100 \%$ própria \\
\hline & Toda a frota possui seguro \\
\hline & Investimento em melhoria da frota através das manutenções frequentes \\
\hline & Há sistema de roteirização \\
\hline & $\begin{array}{l}\text { Há premiação na forma de disnheiro para os motoristas que realizam as entregas de forma } \\
\text { correta }\end{array}$ \\
\hline & Não há investimentos em melhoria de combustível utilizado \\
\hline
\end{tabular}

Quadro 4. Dvisão das respostas do questionário nos aspectos sociais, ambientais e econômicos.

Fonte: Elaborado pelo autor. 


\subsection{Terceiro passo}

Nesta etapa é realizada a técnica de modelagem sistêmica chamada de CATWOE.

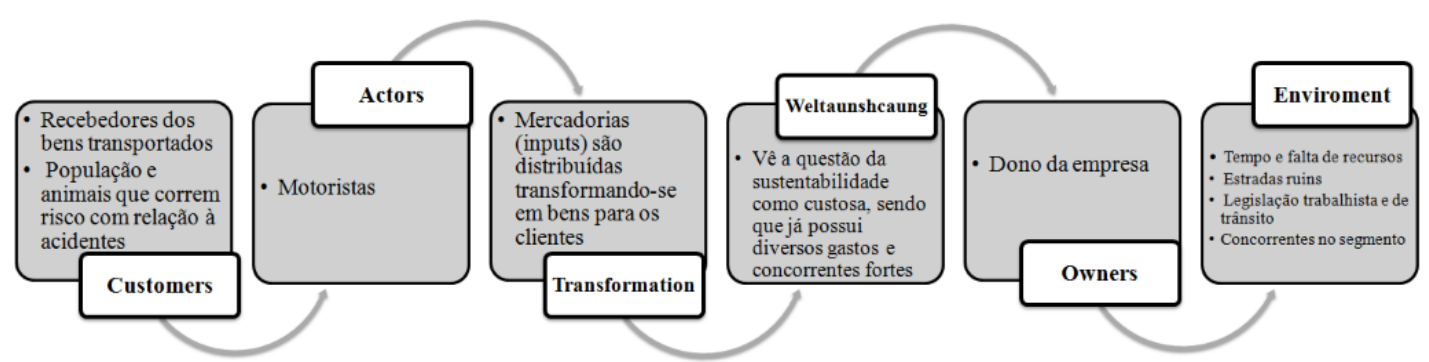

Fig. 2. Representação da modelagem C'ÁlWUE.

Fonte: Elaborado com base em Ferrola, Passador e Passador (2012).

\subsection{Quarto passo}

São elaborados modelos conceituais ideais, ou seja, são propostas algumas alternativas possíveis que podem ajudar na resolução da situação-problema. Foram criadas dez medidas para tal, descritas a seguir:

a) Oferecer seguro de vida aos motoristas, afinal, é uma profissão que está frequentemente correndo risco de vida;

b) Ampliar o apoio psicológico principalmente relacionado aos desvios de condutas dos 101 motoristas contratados, pois apenas uma pessoa não consegue realizar o atendimento de forma eficaz no que tange à quantidade de funcionários que precisam do serviço;

c) Realizar campanhas sociais com engajamento dos funcionários ligando o desempenho dos mesmos ao bônus recebido no final do ano. Como exemplo, ajuda à ONGs, patrocínio de causas solidárias, desenvolvimento de ações voluntárias pelos funcionários;

d) Realizar pesquisas de clima organizacional e entrevistas de desligamento, para saber se o funcionário está satisfeito ou não com a empresa, onde ela pode melhorar e qual a taxa de turn-over;

e) Fazer parte do Programa Na Mão Certa, que é um programa que tem como objetivo propor ações para acabar com a exploração sexual de crianças e adolescentes nas rodovias brasileiras;

f) Realizar campanhas para minimizar o consumo de água e energia, e também algum programa para minimização da degradação ambiental urbana, como por exemplo, a revitalização de praças e calçadas;

g) Orientação do recrutamento e seleção para aumentar a diversidade de gênero, pois tendo interesse nessa diversidade, a empresa não ganha apenas na questão ideológica e igualitária, mas também na questão estratégica, atribuindo uma vantagem competitiva;

h) Distribuir pontos de coleta de pilhas e baterias tanto nos armazéns quanto nos escritórios para o descarte adequado de tais resíduos;

i) Premiação para o motorista que consiga manter o veículo em condições adequadas, evitando maiores impactos negativos ao meio ambiente;

j) Manutenção da frota em oficinas de concessionárias ou homologadas com relação ao descarte adequado dos resíduos sólidos dos caminhões (pneus, funilaria, óleo). Além do monitoramento das condições de emissão de particulados, gases e fumaças da frota terceirizada.

As propostas podem ser visualizadas a partir da dimensão que envolve, conforme o quadro-resumo a seguir: 


\begin{tabular}{|c|c|}
\hline Dimensão & Medidas \\
\hline Social & 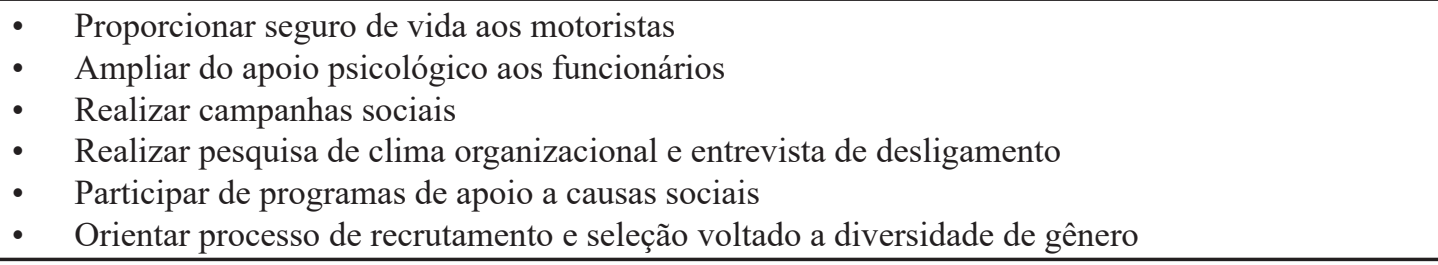 \\
\hline Ambiental & $\begin{array}{l}\text { - Realizar campanhas para minimizar o consumo de água e energia } \\
\text { - } \quad \text { Pistribuir pontos de coleta de pilhas e baterias } \\
\text { o veículo em condições adequadas } \\
\text { - Proporcionar descarte adequado de resíduos sólidos dos caminhões } \\
\text { - Monitorar a emissão de poluentes dos caminhões }\end{array}$ \\
\hline Econômica & $\begin{array}{l}\text { - Proporcionar seguro de vida aos motoristas } \\
\text { - Realizar campanhas para minimizar o consumo de água e energia } \\
\text { Premiação para motoristas que contribuem para redução do impacto ao meio-ambiente, mantendo } \\
\text { o veículo em condições adequadas }\end{array}$ \\
\hline
\end{tabular}

Quadro 5. Quadro-Resumo das Medidas Propostas

Fonte: Elaborado pelo autor.

\subsection{Quinto passo}

Trazendo este modelo conceitual para a realidade, afinal, a empresa em questão está em um ramo extremamente competitivo e, dentre as cinco empresas distribuidor-atacadistas de Uberlândia, ela é a menor, fazendo com que haja empecilhos para investir em sustentabilidade.

Portanto, das dez alternativas propostas, são escolhidas as principais, ou seja, as que possuem maior urgência para serem implementadas na empresa.

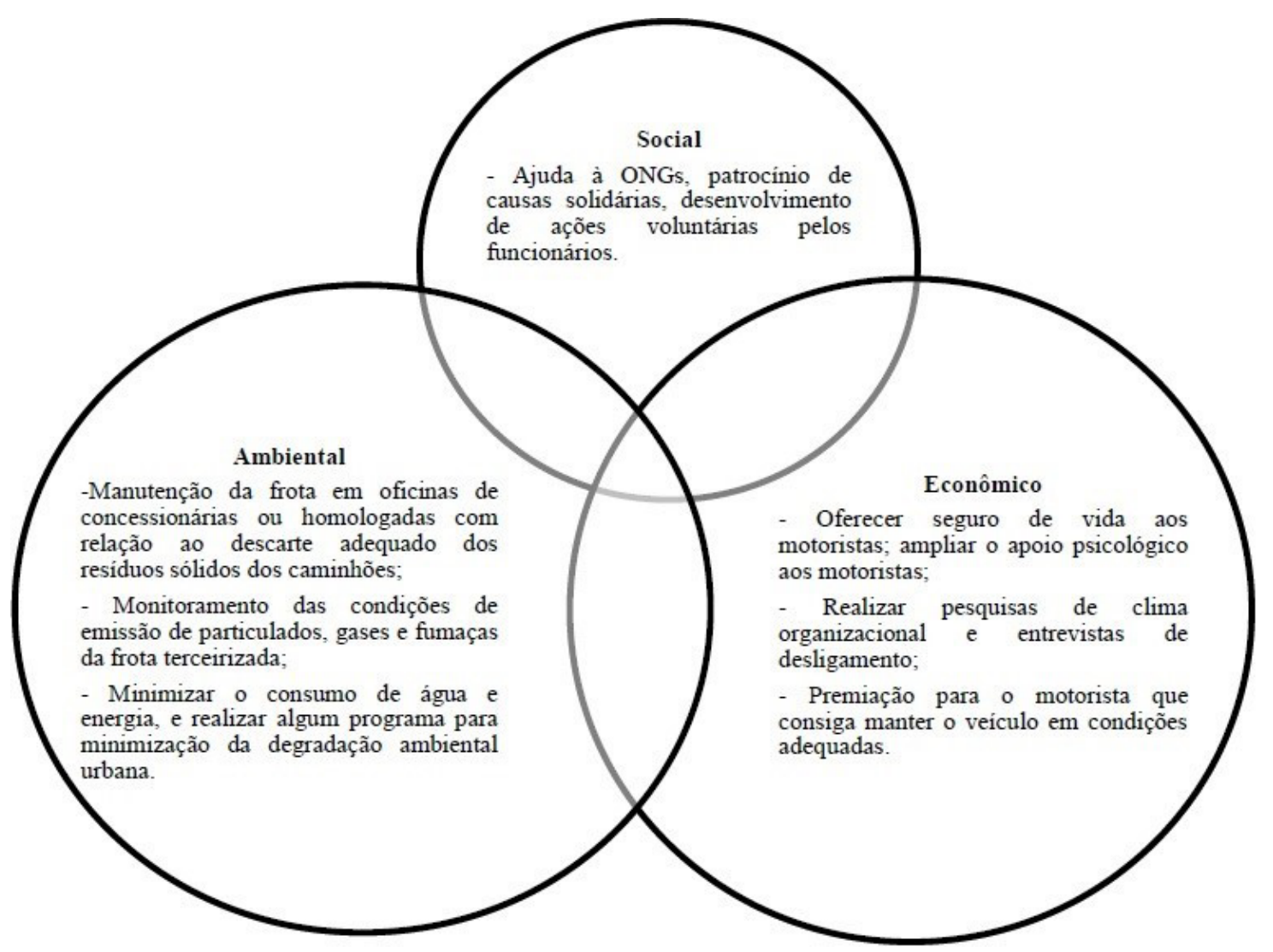

Fig. 3. Alternativas mais importantes a serem tomadas em cada uma das três esferas da sustentabilidade

Fonte: Elaborado pelo autor. 


\subsection{Sexto passo}

Para obter sucesso na implementação das medidas, deve-se começar por ações de educação aos funcionários, para conscientizá-los da importância da adoção de tais medidas, que pela entrevista percebeu-se que tal consciência é um pouco falha. Seguindo para as ações ambientais para a frota e finalmente, para as ações sociais, que demandam mais tempo, pois é necessário fazer parcerias. Portanto, o tempo necessário para lograr a instalação de todas as medidas indispensáveis para a empresa é de no mínimo três anos.

Como ponto crítico, encontrou-se a falta de capacitação dos funcionários, até mesmo dos trabalhadores da área administrativa, que não são aptos para coordenar tais mudanças. Para solução desse impasse pode-se sugerir que a empresa crie um instituto social ou uma fundação para facilitar a efetivação das medidas através da capacitação dos funcionários.

Para colocar as ações ambientais em prática é necessária a consciência ambiental de todos os funcionários, mas principalmente, por parte dos gestores, para que estes tenham o direito de cobrar medidas sustentáveis e que não agridam o ambiente por meio de exemplo dado aos demais funcionários. Para as ações econômicas serem colocadas em prática é necessária a visão de que o motorista é o elemento principal da empresa, sendo dada a devida importância que ele tem. E finalmente para colocar as ações sociais em prática, a principal medida que deve ser adotada é a realização de parcerias com ONGs ou até mesmo com a Prefeitura para a realização de projetos sociais.

\subsection{Sétimo passo}

No último passo é feito uma generalização das medidas, como se fossem variáveis, para que a situação problemática sobre a sustentabilidade seja resolvida em qualquer empresa do setor ou que ao menos possa servir como base de comparação.

Para a questão social, tem-se as ações filantrópicas, mas as questões de endomarketing ainda não são exploradas que pode estimular a consciência e significado das estratégias aos funcionários. Para a questão ambiental, o foco é a melhoria e conservação da frota, além da preocupação com a diminuição/descarte correta dos resíduos gerados. E para a questão econômica, o foco deve ser o investimento em melhorias para o motorista, pois assim, ele será mais realizado profissionalmente, aumentando a produtividade, segurança, obedecendo às regras com mais qualidade de vida.

\section{Conclusão}

O objetivo do presente trabalho foi propor ações de gestão socioambiental para o setor de distribuição de cargas rodoviárias, tomando como exemplo uma empresa de Uberlândia - MG. Tal objetivo foi atendido pela metodologia SSM utilizada apesar da limitação da não obtenção dos dados de stakeholders que completaria a análise para captar a visão de mundo de todos os atores do sistema. A Soft Systems Methodology se mostrou eficaz no desenrolar do problema, pois mostrou caminhos que não poderiam ter sido vislumbrados em uma primeira impressão, mas que após a aplicação dos sete passos puderam ser elucidados.

A importância do Soft System Methodology (SSM) é confirmada por Venters, Cornford e Cushman (2005) quando afirmam que a SSM considera a realidade social de determinado sistema e é implementada como uma forma de compreensão do mundo. A avaliação pelo SSM possibilita observar a complexidade e mudança sob um ponto de vista que faça sentido, e não como representações de sistemas criados a partir da nossa proposta para o mundo. Segundo Cezarino, Liboni e Martinelli (2005) o SSM é uma ferramenta cibernética 
que permite, por meio da visão do conceito sistêmico, resolver problemas de difícil mensuração, ao fragmentar a complexidade do todo organizacional. Desta maneira, esta metodologia orienta para a implementação direta da solução de um problema.

A problemática apresentada pela empresa pode ser representada pela dificuldade com relação à sustentabilidade. Não são executadas ações básicas, como por exemplo, o investimento em frota ou a reciclagem de material exclusiva da empresa não são sequer mencionados.

Tendo como base esse contexto, foram eleitas três ações consideradas prioritárias para a condução das ações de sustentabilidade, que são: uma para a parte social buscando-se aprimorar a gestão dos benefícios dos funcionários; uma para a parte ambiental, que deve ter como foco a melhoria e conservação da frota e os resíduos gerados; e uma para a parte econômica, tendo o foco o investimento em melhorias de produtividade para o motorista.

Tais ações levam à identificação de variáveis em comum para este ramo de atividade, que são: o trabalho social, a melhoria da frota e do descarte de resíduos e, o investimento no motorista.

Por fim, para contribuições futuras, é necessário o aprofundamento dos questionamentos com outras empresas do setor distribuidor-atacadista para a comparação das ações e possíveis parcerias nas variáveis encontradas pelo método utilizado (SSM).

\section{Referências}

Ballou, R. H. (2009). Gerenciamento da Cadeia de Suprimentos-: Logística Empresarial. Bookman Editora.

Bertaglia, P. R. (2017). Logística e gerenciamento da cadeia de abastecimento. Editora Saraiva.

Bond, E. (2002). Medição de desempenho para gestão da produção em um cenário de cadeia de suprimentos (Doctoral dissertation, Universidade de São Paulo).

Carvalho, A., \& Hourneaux Junior, F. (2012). A sustentabilidade na indústria automobilística: vantagem competitiva ou um sonho distante?. Revista de Administração da Universidade Federal de Santa Maria, 5.

Catani, R. (2016). Proposta de ações sustentáveis a uma empresa distribuidora-atacadista de frota rodoviária (Trabalho de Conclusão de Curso). Universidade Federal de Uberlândia - UFU, Uberlândia, MG, Brasil.

Cezarino, L. O., Liboni, L., \& Martinelli, D. P. (2005). Metodologia SSM e sua aplicação na intervenção organizacional em uma empresa de propaganda. In $1^{\circ}$ Congresso Brasileiro de Sistemas.

Checkland, P. (1981). Systems thinking, systems practice.

Christopher, M. (2007). Logística e gerenciamento da cadeia de suprimentos: criando redes que agregam valor. In Logística e gerenciamento da cadeia de suprimentos: criando redes que agregam valor. 
Coral, E. (2002). Modelo de planejamento estratégico para a sustentabilidade empresarial (Tese de doutorado). Universidade Federal de Santa Catarina - UFSC, Florianópolis, SC, Brasil. Recuperado de https://repositorio. ufsc.br/handle/123456789/82705.

Cota Júnior, M. B. G., Freitas, J. S., \& Cheng, L. C. (2008). Uma análise de soft systems methodology e sua utilização para melhoria do processo de desenvolvimento de cultivares em uma instituição de pesquisa agropecuária. In Embrapa Milho e Sorgo-Artigo em anais de congresso (ALICE). In: Congresso Brasileiro de Sistemas, 3; Congresso Catarinense de Sistemas, 1., 2007, Florianópolis. Pratica sistêmica em situação de complexidade: Anais. Florianópolis: UFSC, 2007.

Council of Supply Chain Management. (2009). Supply Chain Management Definitions and Glossary. Recuperado de: https://cscmp.org/imis0/CSCMP/Educate/SCM_Definitions_and_Glossary_of_Terms/CSCMP/Educate/ SCM_Definitions_and_Glossary_of_Terms.aspx?hkey=60879588-f65f-4ab5-8c4b-6878815ef921.

Cushman, M., Cornford, T., \& Venters, W. (2005). Knowledge about sustainability: SSM as a method for conceptualising the UK construction industry's knowledge environment. Journal of computing and information technology, 13(2), 137-148.

Do Vale, C. C. (2012). Teoria geral do sistema: histórico e correlações com a geografia e com o estudo da paisagem. ENTRE-LUGAR, 3(6), 85-108.

Elkington, J. (1998). Partnerships from cannibals with forks: The triple bottom line of 21st-century business. Environmental Quality Management, 8(1), 37-51.

Ferrola, L. N., Passador, C. S., Passador, J. L. (2012). Aplicação da ferramenta CATWOE enriquecida para mapeamento do sistema de implementação das políticas públicas federais para a educação rural. In Congresso Brasileiro de Sistemas, Poços de Caldas, MG, Brasil, 8.

Huertas, D. M. (2014). O papel do transporte rodoviário de carga em Uberlândia, epicentro logístico do setor atacadista-distribuidor. Sociedade \& Natureza.

Instituto Filantropia. (2008). Triple Bottom Line: O tripé da sustentabilidade. Recuperado de http://www. institutofilantropia.org.br/component/k2/item/1607triple_bottom_line_o_tripe_da_sustentabilidade.

Martinelli, D. P., \& Ventura C. A. A. (2006). Visão Sistêmica e Administração: conceitos, metodologias e aplicações. São Paulo: Saraiva, 242.

Ministério dos Transportes. (2018). Secretaria de Política Nacional de Transportes. Projeto de Reavaliação de Estimativas e Metas do PNLT. 
MRS Estudos Ambientais Ltda. (2005). Relatório de impacto ambiental-RIMA da Unidade 3 da central nuclear Almirante Álvaro Alberto. Recuperado de http://www.eletronuclear.gov.br/Portals/0/RIMAdeAngra3/07 identificacao.html.

Novaes, A. (2007). Logística e gerenciamento da cadeia de distribuição. Elsevier Brasil.

Orsato, R. J., \& Wells, P. (2007). U-turn: the rise and demise of the automobile industry. Journal of Cleaner Production, 15(11-12), 994-1006.

Pagell, M., \& Wu, Z. (2009). Building a more complete theory of sustainable supply chain management using case studies of 10 exemplars. Journal of supply chain management, 45(2), 37-56.

Patching, D. (1992). Seeking out the issues. OR Insight, 5(1), 9-14.

Piovesan, A., \& Temporini, E. R. (1995). Pesquisa exploratória: procedimento metodológico para o estudo de fatores humanos no campo da saúde pública. Revista de Saúde Pública, 29, 318-325.

Pires, S. R. (2004). Gestão da Cadeia de Suprimentos (Supply Chain Management)-Conceitos, Estratégias e Casos. São Paulo: Atlas.

Programa Na Mão Certa. (2006). Recuperado de http://www.namaocerta.org.br/programa.php.

Pullman, M. E., Maloni, M. J., \& Carter, C. R. (2009). Food for thought: social versus environmental sustainability practices and performance outcomes. Journal of Supply Chain Management, 45(4), 38-54.

Seuring, S., \& Müller, M. (2008). From a literature review to a conceptual framework for sustainable supply chain management. Journal of cleaner production, 16(15), 1699-1710.

Silva, R. D., Leite, M. O., Silva, A. A. D., Paula, O. L. F. D., \& Osterne, F. J. W. (2000). Infraestrutura e facilidades logísticas como estratégias de vantagem competitiva no processo de desenvolvimento sustentável: o caso da cidade de Uberlândia-MG. Encontro Nacional de Engenharia de Produção, 20.

United Nations Statistics Dividion. (2015). Detailed structure and explanatory notes. Recuperado de http:// unstats.un.org/unsd/cr/registry/regcs.asp? $\mathrm{Cl}=9 \& \mathrm{Lg}=1 \& \mathrm{Co}=6$.

United Nations. (1987). General Assembly, Report of the World Comission on Environment and Development.

Vachon, S., \& Klassen, R. D. (2006). Green project partnership in the supply chain: the case of the package printing industry. Journal of Cleaner production, 14(6-7), 661-671. 
Venturi, M. J., Oliveira, M. R., Andrade, D. A. C., \& Medeiros, D. G. (2005). Aplicação da Metodologia SSM (Soft Systems Methodology) na dinâmica do fluxo de informações da área de logística em uma cervejaria. In Proceedings of the 1st International Society for the Systems Sciences-Brazilian Chapter Systems Conference, Univ. of São Paulo, Brazil.

Vergara, S. C. (2000). Projetos e relatórios de pesquisa em administração. São Paulo: Atlas. project management: the main findings of a UK government-funded research network". International Journal of Project Management, 24(8), 638-649.

Wood, T. (1998). Supply Chain Management: uma abordagem estratégica para a logística empresarial (No. 5). Escola de Administração de Empresas de São Paulo, Fundação Getúlio Vargas, Núcleo de Pesquisas e Publicações. 